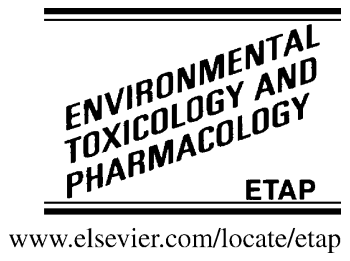

\title{
Behavioral and neurotoxicological effects of subchronic manganese exposure in rats
}

\author{
Tünde Vezér ${ }^{\mathrm{a}, *}$, András Papp ${ }^{\mathrm{a}}$, Zsófia Hoyk ${ }^{\mathrm{b}}$, Csaba Varga ${ }^{\mathrm{b}}$, \\ Miklós Náray ${ }^{\mathrm{c}}$, László Nagymajtényi ${ }^{\mathrm{a}}$ \\ ${ }^{a}$ Department of Public Health, University of Szeged, Dóm tér 10, H-6720 Szeged, Hungary \\ ${ }^{\mathrm{b}}$ Biological Research Center of the Hungarian Academy of Sciences, Szeged, Hungary \\ ${ }^{\mathrm{c}}$ National Center for Public Health, Budapest, Hungary
}

Available online 30 January 2005

\begin{abstract}
In male Wistar rats, behavioral and electrophysiological investigations, and blood and brain manganese level determinations, were performed; during 10 weeks treatment with low-dose manganese chloride and a 12 weeks post-treatment period. Three groups of 16 animals each received daily doses of 14.84 and $59.36 \mathrm{mg} / \mathrm{kg}$ b.w. $\mathrm{MnCl}_{2}$ (control: distilled water) via gavage. During treatment period, $\mathrm{Mn}$ accumulation was seen first in the blood, then in the brain samples of the high-dose animals. Short- and long-term spatial memory performance of the treated animals decreased, spontaneous open field activity (OF) was reduced. The number of acoustic startle responses (ASR), and the pre-pulse inhibition (PPI) of these, diminished. In the cortical and hippocampal spontaneous activity, power spectrum was shifted to higher frequencies. The latency of the sensory evoked potentials increased, and their duration, decreased. By the end of the post-treatment period, Mn levels returned to the control in all samples. The impairment of long-term spatial memory remained, as did the number of acoustic startle responses. Pre-pulse inhibition, however, returned to the pre-treatment levels. The changes of the open field activity disappeared but a residual effect could be revealed by administration of D-amphetamine. The electrophysiological effects were partially reversed.

By applying a complex set of methods, it was possible to obtain new data for a better-based relationship between the known effects of Mn at neuronal level and the behavioral and electrophysiological outcomes of Mn exposure.

(C) 2005 Elsevier B.V. All rights reserved.
\end{abstract}

Keywords: Manganese chloride; Maze learning; Spontaneous locomotor activity; Cortical activity; Acoustic startle response; GFAP

\section{Introduction}

Manganese $(\mathrm{Mn})$ is, in small amounts, an essential micronutrient (WHO, 1981), being cofactor in metalloenzymes. In prolonged exposure to higher doses it is, however, a potential environmental neurotoxicant. In the general population, excess dietary intake (beyond the estimated safe and adequate daily amount) is more typical, as in case of babies fed by cow milk or soybean-based formulas (Marlowe and Bliss, 1993), or in the population having environmental exposure via the drinking water. In Greece, $50 \mathrm{mg} / \mathrm{l} \mathrm{Mn}$ in the drinking water was associated with neurological effects (Kondakis et al., 1989). Mn as man-made environmental con-

\footnotetext{
* Corresponding author. Tel.: +36 62545 119; fax: +36 62545120 .

E-mail address: vezer@puhe.szote.u-szeged.hu (T. Vezér).
}

taminant originates from Mn-containing waste (e.g. batteries), methylcyclopentadienyl manganese tricarbonyl (MMT) used as anti-knock petrol additive, and organo-Mn agricultural fungicides (ATSDR, 2000).

Following ingestion, inorganic $\mathrm{Mn}$ is absorbed in the intestine mostly in trivalent form (Cotzias et al., 1971) in a homeostatic self-limiting process. The main sites of deposition are the mitochondria-rich tissues, e.g. liver, pancreas, pituitary gland and the muscles (Barceloux, 1999). Brain is among the primary target organs in chronic Mn exposure (Roels et al., 1987), and the turnover of Mn there is much slower than in other parts of the body (Feldman, 1992).

In subchronic dosage, Mn appears in the cerebral and cerebellar cortex (Dorman et al., 2000). In case of chronic intake, $\mathrm{Mn}$ is found in motor control centers such as the basal ganglia, particularly the globus pallidus, striatum and substantia ni- 
gra where it causes degeneration (Yamada et al., 1986). Mn accumulation was also described in the pons and medulla (Chan et al., 1992), and in the hippocampus (Takeda et al., 1998).

The high sensitivity of different behavior types and the integration of different (motor, sensory, attentional, motivational) behavioral functions is especially important in assessment neurotoxic risk due, e.g. to Mn. Excess Mn was shown to cause several neurotoxic effects such as childhood hyperactivity disorder (Barlow, 1983), manganese psychosis, extrapyramidal dysfunction (Quaghebeur et al., 1996), motor deficit (above $7.5 \mu \mathrm{g} / \mathrm{l}$ blood Mn; Mergler et al., 1999); as well as altered childhood psychomotor development (Takser et al., 2003) and impairments of several memory process (list learning, visual recognition, digit span). Lucchini et al. (1999) found irritability and motor functional damage in exposed workers having ca. $10 \mu \mathrm{g} / \mathrm{l}$ blood Mn level. A child developed severe epilepsy following exposure to welding fumes resulting in 15-20 $\mu \mathrm{g} / \mathrm{l}$ blood Mn (Hernandez et al., 2003).

Similar deficits were also induced by $\mathrm{Mn}$ in animals. Öner and Sentürk (1992) saw impaired T-maze learning in rats receiving $375 \mu \mathrm{g} / \mathrm{kg}$ b.w. Mn for 30 days. Ingersoll et al. (1995) elicited spontaneous hypoactivity by intrathecal administration of $\mathrm{MnCl}_{2}$. Dorman et al. (2000) described altered acoustic startle responses (ASR) in neonatal rats receiving 25 and $50 \mathrm{mg} / \mathrm{kg}$ b.w. $\mathrm{MnCl}_{2}$.

Significant relationship between neurotoxic alterations, neurotransmitter or modulator metabolism (first of all catecholamines), and Mn exposure have been described (Neff et al., 1969). Mn, in case of prolonged low level exposure, accumulates in the nigrostrial dopaminergic pathway (Subhash and Padmashree, 1991). The resulting dopaminergic-glutamatergic interactions are involved in the Mn effects on extrapyramidal motor functions and, indirectly, in the sensorimotor integration (Calabresi et al., 1997).

Direct toxicity of Mn to dopaminergic neurons was described by Parenti et al. (1987). The involvement of other transmitters can result from dopaminergic control upon these (Takeda et al., 2002) or by direct effect of Mn. The latter is know to exist in the GABAergic (Trepper et al., 1998) and glutamatergic system. Reduced glial glutamate uptake (Aschner et al., 1999) leads, as a direct result of impaired astrocytic-neuronal interactions (Hazell, 2002), to increased extracellular glutamate concentration, the excitotoxic effect of which could play a key role in manganeseinduced neuronal cell death. Marked reactive astrocytosis, with significant hypertrophy of glial fibrillary acid proteinimmunoreactive-GFAP-IR - astrocytes, was seen on Mn exposure in the globus pallidus (Baeck et al., 2003). In the hippocampal dentate gyrus, Mn exposure caused a decrease of GFAP-IR area in juvenile, but an increase in adult, rats (Pappas et al., 1997). This, together with the numerous effects of Mn exposure on the behavior, raised the possibility that these functional and morphological changes induced by Mn develop in parallel and are in detectable causal relationship.
There has been ample literature on the negative effects of $\mathrm{MnCl}_{2}$ on behavioral outcomes in rats. Several mechanisms have been purposed, such as influence on transmitter systems (Tran et al., 2002; Gwiazda et al., 2002), or directly on structural elements like hippocampal astrocytes (Aschner, 1996) and the midbrain and basal ganglia (Erikson and Aschner, 2002). The dentate gyrus (primarily the granule cells) plays an important role in the acquisition of new information (Ogura et al., 2002) and is possibly neural substrate of spatial reference and working memory, and of synaptic plasticity (Ikegaya et al., 1995). Agents acting on the dentate gyrus possibly affect learning and memory performance, locomotor activity, radial maze performance and spontaneous motor activity, and psychomotor performance.

In the works cited above, however, behavioral effects were not supported by histochemical or electrophysiological findings, and no follow-up in the after-exposure period was included. The electrophysiological effect of Mn exposure is in itself an open question: some authors found disturbances of spontaneous or stimulus-evoked cortical activity in workers exposed to comparable airborne Mn levels (Sinczuk-Walczak et al., 2001) while others did not (Deschamps et al., 2001).

Hence, our experiment involved a complex behavioral test battery ( 8 -arm radial maze, open field activity-OF, acoustic startle response-ASR, and pre-pulse inhibition-PPI). Our behavioral investigations were supplemented by cortical electrophysiology (electrocorticogram-ECoG, evoked potentials-EP), immunhistochemistry (GFAP in various parts of the hippocampus), and by Mn level determination in blood, cortex and hippocampus. All investigations were performed both during and after the period of Mn administration. It was also attempted to prove the involvement of the dopamine (DA) system by applying a dopaminergic agonist in the elimination period.

\section{Methods}

\subsection{Animals, housing, treatment}

Young adult male Wistar rats (220-250g body weight at start), obtained at the University's Breeding Center, were used. The animals were housed under controlled conditions of temperature $\left(22-24^{\circ} \mathrm{C}\right)$ and photoperiod (12-h light:12-h dark cycle with light starting at 06:00 h), with free access to drinking water. Three weeks before starting the treatment, the animals (up to 4 rats per cage) were put in cages of $28 \mathrm{~cm} \times 40 \mathrm{~cm} \times 20 \mathrm{~cm}$. The memory test used required that during the 10 weeks of treatment the animals had a restricted access to food ( $1 \mathrm{~h} /$ day) resulting in a mild (ca. 20-25\%) body weight loss (Beatty and Shavalia, 1982). Body weight was measured and the animals' general state was observed every day.

The rats were divided into three groups, consisting of 16 animals each at start. One group was treated with 14.84 (low dose group), and another one with 59.36 (high dose 
group), $\mathrm{mg} / \mathrm{kg}$ b.w. inorganic $\mathrm{Mn}\left(\mathrm{MnCl}_{2} \cdot 4 \mathrm{H}_{2} \mathrm{O}\right.$, minimum 99\% purity, REANAL Hungary) dissolved in distilled water to $1 \mathrm{ml} / \mathrm{kg}$ administration volume, given by gavage, 5 days a week, for 10 weeks (Table 1). These doses were 1/100 and $1 / 25$ of the acute oral rat-LD $\mathrm{L}_{50}$, taken from the safety data for manganese(II) chloride tetrahydrate (Physical and Theoretical Chemistry Laboratory, 2001). (Our own LD50 determination gave a similar value. Literature with comparable figures, referred to in Section 1, indicated that this dose range is likely to cause behavioral alterations.) Animals in the third (control) group received distilled water.

The whole study was done in adherence to the requirements by the Ethical Committee for the Protection of Animals of the University.

\subsection{Time scheme of the tests performed}

The time scheme of the whole experiment, and the number of animals used, is summarized in Table 1. The experiment lasted 22 weeks, whereby the 0th week was pre-treatment period, the treatment period involved the 1st to 10th weeks, and the 11th to 22 nd weeks constituted the post-treatment period.

The spatial maze learning and memory test were done throughout the whole treatment period. In the 0th, 5th and 10th week, a subset of 12 per group was tested for locomotor activity, and in the 5th and 10th week, for acoustic startle response. In the 5th week, three rats per group underwent electrophysiological recording, and were sacrificed for blood and tissue sampling to determine Mn content (blood samples were also taken in the 0th week). In the 10th week, five animals per group were used for electrophysiological recording and sacrificed for blood and tissue sampling; and another two per group were sacrificed for GFAP histochemistry (see Section 2.4). The remaining six animals per group were kept for further 12 weeks, during which spatial memory, locomotor activity and acoustic startle tests were repeated to see any elimination of $\mathrm{Mn}$ and disappearance of its effects. Finally, electrophysiological recording, and blood and tissue sampling, was done on these animals.

\subsection{Behavioral tests}

The maze and open field tests were done between 08:00 and 14:00 h, in a room of low illumination and noise level, different from that used for keeping and treating the animals. Acoustic startle response and pre-pulse inhibition test were performed under identical conditions later in the day.

\subsubsection{Test procedure for spatial learning and memory}

The animals' spatial learning ability was tested in an 8arm radial maze (Columbus Instruments, Ohio, USA). In the 1st week of treatment period (Table 1), the animals had 10min training sessions twice a day whereby they were (under partial food deprivation, see above) adapted to find food pellets in the maze arm ends. During acquisition (Acquisition in
Table 1), with one training per day, the rats learned to visit the farthest points of each arm. This way, the rats were forced to acquire a win-shift food-rewarded learning strategy (Beatty and Shavalia, 1982). The rate of correct responses was given in percents. (Incorrect responses consisted of revisiting an arm previously visited in the same session.) All animals had a run performance of over $85 \%$. Based on this memory content, the following tests were performed:

Short term spatial working memory tests were done in the 3 rd and 5th treatment week (Mem $2 h$ and Mem $4 h$; Table 1). The rats were one by one put for 10 min maximum in the center of the maze, but were allowed to enter only four of the eight open and baited arms (at their own random selection); this was the "event-to-be-remembered". After visiting the four arms, the animal was returned to its cage and kept there for 2 or $4 \mathrm{~h}$. The rat was then put again in the maze center and allowed to complete arm choices 5-8 to obtain rewards in the four baited arms not visited before. In the working memory tests, errors (WM error) meant reentry into any of the baited arms visited in the first run. Working memory performance was thus counted as [(correct responses - WM errors $) \times 100]$.

Reference memory was tested in the 4th week with 16 rats per group. Here, food reward was put only in the four arms preferred by the individual rats. Entering an unbaited arm constituted a reference memory error, from which performance was calculated as above.

Rest periods, lasting 2 weeks, were introduced twice: in the 6th to 7 th treatment weeks and in the 1 st to 2 nd post-treatment weeks. In these times, the animals were kept in the housing room, did not have any testing, and were not exposed to new information.

Long-term working memory (retention) tests were done in the 8 th to 10 th treatment, and 3rd to 5th post-treatment weeks. In the 8th week, memory return was observed, and in the 9th and 10th week, 2- and 4-h working memory (Mem $R 2 h$ and Mem $R 4 h$; Table 1). This sequence was repeated in the post-treatment period (Returm(e), Mem(e)R $2 h, \operatorname{Mem}(e) R 4 h$; Table 1).

\subsubsection{Locomotor activity}

The rats' spontaneous motor behavior was assessed, using a fixed subset of 12 rats from each group, in the 0th, 5th and 10th week of treatment phase, and, with six rats (of the 12 tested previously) per group, in the 7th posttreatment week (Table 1). The test was performed always once in the given weeks, following the maze-learning session. The animals were first allowed to accommodate in the testing room for 30-40 min. An open field (OF) box of $40 \mathrm{~cm} \times 40 \mathrm{~cm} \times 40 \mathrm{~cm}$ size (ACTIFRAME, Gerb Electronic, Berlin, Germany), equipped with two arrays (at 3 and $15 \mathrm{~cm}$ above floor level) of infrared movement detectors with $1.1 \mathrm{~cm}$ distance between the beams, was used. Illumination at the floor of the OF was $12-25 \mathrm{~lx}$, with ca. $40 \mathrm{~dB}$ white background noise. The animals were placed into the center 
Table 1

Time scheme of experiment (lasting from the 0th to the 22nd weeks) - the pre-treatment week and treatment (A) and post-treatment (B) period

\begin{tabular}{|c|c|c|c|c|c|c|c|c|c|c|c|c|c|c|c|c|c|}
\hline \multirow[t]{2}{*}{ Investigations } & \multirow{2}{*}{\multicolumn{2}{|c|}{$\begin{array}{l}\text { Pre-treatment } \\
\text { week } \\
\text { Oth }\end{array}$}} & \multicolumn{15}{|c|}{ Weeks of the $\mathrm{MnCl}_{2}$-treatment period (1st to 10 th experimental weeks) } \\
\hline & & & \multicolumn{2}{|l|}{1 st } & \multicolumn{2}{|c|}{ 2nd } & \multicolumn{2}{|l|}{$3 \mathrm{rd}$} & \multicolumn{2}{|l|}{ 5th } & 6th & \multicolumn{2}{|l|}{ 7th } & 8 th & \multicolumn{2}{|l|}{ 9th } & 10th \\
\hline \multicolumn{18}{|l|}{ (A) } \\
\hline Learning and memory tests & \multicolumn{2}{|l|}{-} & \multicolumn{2}{|c|}{$\begin{array}{l}\text { Adaptation } \\
(3 \times 16)\end{array}$} & \multicolumn{2}{|c|}{$\begin{array}{l}\text { Acquisition } \\
(3 \times 16)\end{array}$} & $\begin{array}{l}\text { Mem 2h } \\
(3 \times 16)\end{array}$ & $\begin{array}{l}\text { Reference } \\
(3 \times 16)\end{array}$ & \multicolumn{2}{|c|}{$\begin{array}{l}\text { Mem 4h } \\
(3 \times 16)\end{array}$} & $\begin{array}{l}\text { Rest } \\
(3 \times 13)\end{array}$ & \multicolumn{2}{|c|}{$\begin{array}{l}\text { Rest } \\
(3 \times 13)\end{array}$} & $\begin{array}{l}\text { Return } \\
(3 \times 13)\end{array}$ & \multicolumn{2}{|c|}{$\begin{array}{l}\text { Mem R 2h } \\
(3 \times 13)\end{array}$} & $\begin{array}{l}\text { Mem R 4h } \\
(3 \times 13)\end{array}$ \\
\hline Open field & \multicolumn{2}{|l|}{$(3 \times 12)$} & \multicolumn{2}{|c|}{-} & \multicolumn{2}{|c|}{-} & - & - & \multicolumn{2}{|c|}{$(3 \times 12)$} & - & \multicolumn{2}{|c|}{-} & - & \multicolumn{2}{|c|}{-} & $(3 \times 12)$ \\
\hline ASR/PPI & \multicolumn{2}{|l|}{-} & \multicolumn{2}{|l|}{-} & \multicolumn{2}{|l|}{-} & - & - & \multicolumn{2}{|c|}{-} & - & \multicolumn{2}{|l|}{-} & - & \multicolumn{2}{|l|}{-} & $(3 \times 12)$ \\
\hline Electrophysiology & - & & - & & - & & - & - & \multicolumn{2}{|c|}{$\begin{array}{l}\text { ECoG, EP } \\
(3 \times 3)\end{array}$} & - & \multicolumn{2}{|l|}{-} & - & \multicolumn{2}{|l|}{-} & $\begin{array}{l}\text { ECoG, EP } \\
(3 \times 5)\end{array}$ \\
\hline Histology & - & & - & & - & & - & - & - & & - & - & & - & - & & $(3 \times 2)$ \\
\hline Mn content in: & blood $(3 \times$ & & - & & - & & - & - & $\begin{array}{l}\text { Bloc } \\
\text { hipp }\end{array}$ & $\begin{array}{l}\text { d, cortex, } \\
\text { c. }(3 \times 3)\end{array}$ & - & - & & - & - & & $\begin{array}{l}\text { Blood, cortex, } \\
\text { hippoc. }(3 \times 5)\end{array}$ \\
\hline Investigations & Weeks of $\mathrm{t}$ & ne post- & t-treat & & & n) perio & (11th to & 2nd experimental & veeks) & & & & & & & & \\
\hline & $1 \mathrm{st}$ & 2nd & & $3 \mathrm{rd}$ & & 4 th & & 5 th & 6 th & 7th & 8 th & & 9th & 10th & & 11th & 12 th \\
\hline (B) & & & & & & & & & & & & & & & & & \\
\hline Learning and memory tests & $\begin{array}{l}\text { Rest(e) } \\
(3 \times 6)\end{array}$ & $\begin{array}{l}\text { Rest( } \\
(3 \times(\end{array}$ & & $\begin{array}{l}\text { Retu } \\
(3 \times\end{array}$ & & $\begin{array}{l}\operatorname{Mem}( \\
(3 \times 6\end{array}$ & $\mathrm{R} 2 \mathrm{~h}$ & $\begin{array}{l}\operatorname{Mem}(e) R 4 h \\
(3 \times 6)\end{array}$ & - & - & - & & - & - & & - & - \\
\hline Open field & - & - & & & & - & & - & - & $(3 \times 6)$ & $0.5 \mathrm{D}-\mathrm{A}(3 \times$ & & - & $1.5 \mathrm{D}-\mathrm{A}(3$ & $\times 6)$ & - & - \\
\hline ASR/PPI & - & - & & & & - & & - & - & $(3 \times 6)$ & - & & - & - & & - & - \\
\hline Electrophysiology & - & - & & & & - & & - & - & - & - & & - & - & & - & $\begin{array}{l}\text { ECoG, EP } \\
(3 \times 6)\end{array}$ \\
\hline Mn content in: & - & - & & & & - & & - & - & - & - & & - & - & & - & $\begin{array}{l}\text { Blood, cortex, } \\
\text { hippoc. }(3 \times 6)\end{array}$ \\
\hline
\end{tabular}

Return(e), second memory return in the post-treatment (elimination) period; Mem(e)R 2h, 2-h working memory after second return; Mem(e)R $2 \mathrm{~h}, 2$-h working memory after second return; D-A, D-amphetamine. 
of the box and their spontaneous horizontal (running), vertical (rearing) and local (predominantly grooming) activity was scored during a 10 min session. Movement scores were computed on the basis of beam interruptions with a PC software having preset conditions to discriminate between forms of movement.

\subsubsection{Amphetamine-induced locomotor activity}

D-Amphetamine (D-A) is known to pass the blood-brain barrier and increase the release of catecholamines (including DA) from presynaptic endings (Clarkson et al., 1988). On the 8 th and 10th post-treatment week, the same rats tested before in the open field were i.p. injected with 0.5 or $1.5 \mathrm{mg} / \mathrm{kg}$ b.w. of D-A, respectively (Table 1). Fifteen minutes later, their OF activity was recorded again.

\subsubsection{Acoustic startle response and pre-pulse inhibition}

The ASR and PPI test was performed on the same animals as the OF test, in the 10th treatment and 7th posttreatment week (Table 1). In this test of sensorimotor control and gating (Feifel et al., 1999), whole body muscle twitch as a response to a sudden acoustic stimulus is measured. A commercially available reflex monitor (Responder X System, Columbus Instruments, Ohio, USA) was used. The animals were, one by one, put in the plexiglass test cage $(16 \mathrm{~cm} \times 28 \mathrm{~cm} \times 18 \mathrm{~cm})$ the floor of which was a piezo force transducer, enclosed within a light- and soundattenuated chamber. After a 10-min accommodation, a series of 10 consecutive tones $(5 \mathrm{kHz}, 110 \mathrm{~dB}, 200 \mathrm{~ms}, 15 \mathrm{~s}$ interval) as test (eliciting) stimuli were applied. To test PPI (representing sensorimotor gating), the eliciting stimuli were in a second series (after $15 \mathrm{~min}$ rest) preceded by inhibiting (non-startling) pre-pulses $(1 \mathrm{kHz}, 73 \mathrm{~dB}, 500 \mathrm{~ms}, 200 \mathrm{~ms}$ delay between pre-pulse and test pulse; Graham, 1975). A whole body twitch resulting in more than $50 \times g$ force to the cage floor was accepted as "noise-positive" response, of which latency, time to peak and peak amplitude were measured. Stimulation and data acquisition was controlled by a PC.

\subsection{Electrophysiology}

After finishing all behavioral tests (i.e. after 5 and 10 weeks of Mn administration and at the end of the posttreatment period), the animals to be recorded (Table 1) were anesthetized with $1000 \mathrm{mg} / \mathrm{kg}$ urethane (Bowman and Rand, 1980), and the left hemisphere was exposed by removing the bony skull. Following a recovery of $30 \mathrm{~min}$ minimum, surface electrodes were placed on the primary somatosensory, visual and auditory cortical focus (Zilles, 1984), and a steel needle electrode was inserted into the hippocampal CA1 region (stereotaxic coordinates: AP -3, L 2, V 2-3; Paxinos and Watson, 1982). Spontaneous electrical activity (electrocorticogram) was recorded for $5 \mathrm{~min}$, and subsequently analyzed for the relative power distribution among the standard frequency bands (delta to gamma; Kandel and Schwartz, 1985).
Then, the surface electrodes were used to record cortical evoked potentials. For somatosensory stimulation, a pair of needles was inserted into the area of the whiskers and rectangular stimuli $(1 \mathrm{~Hz}, 3-4 \mathrm{~V}, 0.2 \mathrm{~ms})$ were applied. Visual stimulation was performed by flashes $(1 \mathrm{~Hz}, 60 \mathrm{~lx})$ delivered by a flashbulb via an optical fiber directly into the contralateral eye of the rat. For acoustic stimulation, clicks $(1 \mathrm{~Hz}, 40 \mathrm{~dB})$, from a small earphone were applied into the contralateral ear of the rat. Fifty stimuli of each modality per rat were applied and the EPs recorded. After averaging, latency and duration of the main waves was measured manually.

All recording of spontaneous and evoked activity and offline analysis was performed by a PC using the NEUROSYS 1.11 software (Experimetria Ltd., UK).

\subsection{Immunohistochemistry}

After finishing behavioral tests in the 10th treatment week, two rats per group (Table 1), were brought to terminal Nembutal anesthesia and were perfused transcardially first with $50 \mathrm{ml}$ physiological saline (pre-rinse) then with $400 \mathrm{ml} 4 \%$ paraformaldehyde fixative solved in $0.1 \mathrm{M}$ phosphate buffer (PB, pH 7.4). The brains were removed from the skull, postfixed for $4 \mathrm{~h}$ and cryoprotected by overnight storage in $30 \%$ sucrose in PB. Coronal sections were cut on a cryostat microtome at a $50 \mu \mathrm{m}$ thickness and collected in phosphate buffered saline.

Immunohistochemical reactions were performed on freefloating sections. After abolishing endogenous tissue peroxidase activity by treatment with $0.6 \% \quad \mathrm{H}_{2} \mathrm{O}_{2}$ in Tris buffered saline (TBS; $0.1 \mathrm{M}, \mathrm{pH} 7.4$ ), the sections were incubated in $5 \%$ normal goat serum (NGS) in TBS containing $0.1 \%$ Triton $\mathrm{X}-100$ for $1 \mathrm{~h}$. Subsequently, tissues samples were incubated in monoclonal anti-GFAP (Sigma, 1:10,000 in TBS containing 0.1\% Triton X-100, $5 \% \mathrm{NGS}$ ) for $16 \mathrm{~h}$ at room temperature. The sections were thoroughly rinsed and exposed to biotinylated goat antimouse IgG (Dianova, 1:300 in TBS containing 5\% NGS) for $1 \mathrm{~h}$. Finally, sections were processed with preformed complexes of streptavidin and biotinylated peroxidase and stained with nickel-enhanced 3,3'-diaminobenzidine as a chromogen.

The density of GFAP-IR was determined for the hippocampal CA1 stratum radiatum and stratum oriens, and for the hilus of the dentate gyrus.

The area of GFAP-IR structures was determined by video imaging using an Image Pro Plus 4.0 image analysis software (Media Cybernetics, Silver Spring, MD, USA). Stained sections were examined under bright field with an Olympus microscope and a $10 \times$ objective. Images were recorded with a SONY 950-P CCD camera (Sony Corp., Japan) and digitized. The program expressed the IR positive area as number of pixels having densities above the threshold. Measurements were taken in a blinded fashion from at least 16 sections for each animal group and averaged. 


\subsection{Tissue manganese level determination}

\subsubsection{Blood collection, cortex and hippocampus sampling}

Blood and tissue samples were collected in the 5th, 10th treatment and 12th post-treatment week from 3, 5 and 6 animals per group, respectively (from three rats per group, blood was also taken in the 0th week). Before the electrophysiological recording, the tail vein was punctured and blood was taken to heparinized vacutainers of $7.0 \mathrm{ml}$ capacity (Becton-Dickinson, BD367735). All blood samples were stored at $4{ }^{\circ} \mathrm{C}$ until analyzed. When the electrophysiological recording was finished, the animals were sacrificed with an overdose of Nembutal, the thorax was opened, and the animals were transcardially perfused with $500 \mathrm{ml}$ saline to remove blood from the organs. The brain was removed whole, without the meninges, and was, under a stereomicroscope, halved and dissected to isolate the hippocampus. The whole hippocampus and $0.3 \mathrm{~g}$ of the cortex was taken as sample, kept at $-18^{\circ} \mathrm{C}$ until analyzed.

\subsubsection{Manganese level determination}

Total manganese content was determined at the accredited laboratory of the National Center for Public Health, Budapest. The samples were digested in $2 \mathrm{ml}$ concentrated nitric acid, with $0.5 \mathrm{ml}$ hydrogen peroxide added for cortex and hippocampus. Total manganese in the samples was determined using a flameless graphite furnace atomic absorption spectrometry.

\subsection{Data and statistical analysis}

The distribution of the data (except the ASR scores) was checked for normality by the Kolmogorov-Smirnov test. Depending on the distribution, the statistical analyses were carried out by one-way ANOVA or Kruskal-Wallis one-way
ANOVA for the maze results, two-way ANOVA for the open field and for tissue manganese content results, and one-way ANOVA for the electrophysiological and morphological results. Dose was chosen for independent variable, and time for second independent variable in two-way ANOVA (in the post-treatment period of the open field tests, time as variable represented the administration of two doses of D-A). The confidence level was set to $p<0.05$ in every case. Post hoc analysis of group differences after ANOVA was performed by the LSD test; and group comparisons following the Kruskal-Wallis test were performed by the Mann-Whitney $U$-test (also here, $p<0.05$ ). The number of animals giving "noise-positive response" in the ASR and PPI tests was evaluated with the $\chi^{2}$-test. For the statistical analysis, Statistica for Windows 4.0 software package was used.

\section{Results}

\subsection{Manganese levels}

Levels of $\mathrm{Mn}$ in various tissues, at the end of the 5th and 10 th week of $\mathrm{MnCl}_{2}$ application and the 12 th post-treatment week, are given in Table 2. Compared to the 0th week (preadministration) value of $0.0181 \pm 0.003 \mu \mathrm{g} / \mathrm{g}$, blood Mn levels increased in a dose- and time-dependent way. In the high dose group, the increase was significant both in the 5th treatment week $\left(F_{2,6}=12.16\right.$; high dose versus control, $p<0.01$; high versus low dose, $p<0.01)$ and in the 10th treatment week $\left(F_{2,12}=9.51\right.$; high dose versus control, $p<0.01$; high versus low dose, $p<0.01)$. By the 12th post-treatment week, the difference between the blood Mn levels in the control and treated groups was no more present.

In the brain samples, a build-up of Mn level was also seen in control animals, indicating preferential deposition. After 5 weeks $\mathrm{MnCl}_{2}$ treatment, cortical $\mathrm{Mn}$ level increased slightly versus control in the high dose group, and hippocam-

Table 2

Manganese content of the blood, cortex and hippocampus samples taken at different times during the experiment (5th and 10th week of treatment, and 12th week of the post-treatment period)

\begin{tabular}{|c|c|c|c|}
\hline \multirow[t]{3}{*}{ Sample } & \multicolumn{3}{|l|}{$\operatorname{Mn}(\mu \mathrm{g} / \mathrm{g})$} \\
\hline & \multicolumn{2}{|l|}{ Treatment } & \multirow{2}{*}{$\begin{array}{l}\text { Post-treatment } \\
\text { 12th week }(n=6)\end{array}$} \\
\hline & 5 th week $(n=3)$ & 10th week $(n=5)$ & \\
\hline \multicolumn{4}{|l|}{ Blood } \\
\hline Control & $0.0314 \pm 0.009$ & $0.0118 \pm 0.002$ & $0.0138 \pm 0.001$ \\
\hline $14.84 \mathrm{mg} / \mathrm{kg}$ & $0.0537 \pm 0.012$ & $0.0164 \pm 0.005$ & $0.0167 \pm 0.003$ \\
\hline $59.36 \mathrm{mg} / \mathrm{kg}$ & $0.3167 \pm 0.136^{* * * \# \#}$ & $0.0364 \pm 0.016^{* *}, \# \#$ & $0.0165 \pm 0.004$ \\
\hline \multicolumn{4}{|l|}{ Cortex } \\
\hline Control & $0.2167 \pm 0.029$ & $0.3134 \pm 0.015$ & $0.3130 \pm 0.032$ \\
\hline $14.84 \mathrm{mg} / \mathrm{kg}$ & $0.2140 \pm 0.032$ & $0.3220 \pm 0.056$ & $0.3095 \pm 0.056$ \\
\hline $59.36 \mathrm{mg} / \mathrm{kg}$ & $0.2823 \pm 0.031$ & $0.4420 \pm 0.107^{*}$ & $0.2872 \pm 0.029$ \\
\hline \multicolumn{4}{|l|}{ Hippocampus } \\
\hline Control & $0.1710 \pm 0.012$ & $0.4604 \pm 0.035$ & $0.5897 \pm 0.102$ \\
\hline $14.84 \mathrm{mg} / \mathrm{kg}$ & $0.2607 \pm 0.085$ & $0.4680 \pm 0.050$ & $0.6022 \pm 0.166$ \\
\hline $59.36 \mathrm{mg} / \mathrm{kg}$ & $0.2307 \pm 0.063$ & $0.6813 \pm 0.138^{* *}, \# \#$ & $0.5662 \pm 0.126$ \\
\hline
\end{tabular}

Mean \pm S.D.; $n$, animals sampled in each group. *, **: $p<0.05,0.01$ high dose vs. control; \#, \#\#: $p<0.05,0.01$ high vs. low dose. 


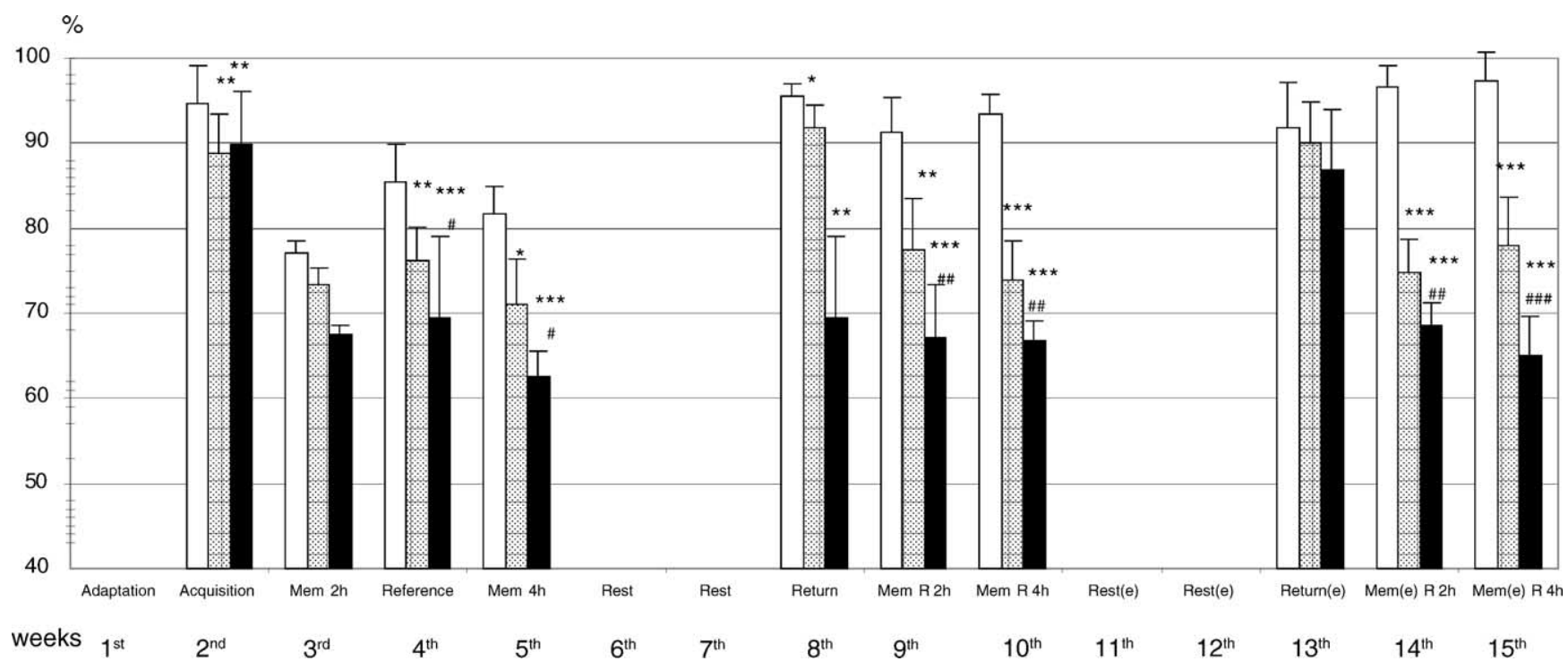

Fig. 1. The animals' memory performance during the whole course of the experiment. Abscissa: weeks and phases of the experiment (1st to 10th experimental weeks, treatment period; 11 th to 15th experimental weeks, post-treatment period; see Table 1). Mem 2h, Mem 4h: 2 and $4 \mathrm{~h}$ working memory; Mem R 2h, Mem R 4h: working memory after memory return; (e) indicates the post-treatment period (phase of elimination). Ordinate: weekly averages (mean \pm S.D.) of the

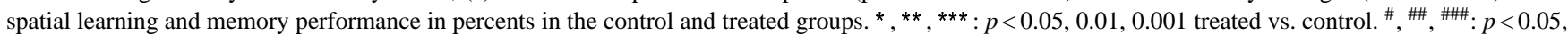
$0.01,0.001$ high vs. low dose. Bar pattern: control ( $\square)$; low dose $(14.84 \mathrm{mg} / \mathrm{kg})($ 圈 $)$; high dose $(59.36 \mathrm{mg} / \mathrm{kg})(\mathbf{\square})$.

pal Mn level, in both treated groups. By the 10th week, the increase became dose-dependently significant both in the cortex $\left(F_{2,12}=5.22\right.$; high dose versus control, $p<0.05$; high versus low dose, $p<0.05)$ and hippocampus $\left(F_{2,15}=9.41 ;\right.$ high dose versus control, $p<0.01$; high versus low dose, $p<0.01$ ). These differences also disappeared during the 12 weeks of post-treatment phase.

\subsection{Maze learning and memory}

During all phases of the spatial maze learning and memory test, including the treatment and post-treatment period, both $\mathrm{MnCl}_{2}$ treated groups showed, compared to control animals, a decrease in the average memory performance (Fig. 1).

Acquisition (2nd treatment week) was dose-dependently impaired in the $\mathrm{MnCl}_{2}$ treated rats $\left(F_{2,15}=7.51\right.$; high dose versus control, $p<0.01$; low, $p<0.05)$. Reference memory (4th treatment week) showed in both treated groups a significant performance deficit $\left(F_{2,12}=24.68\right.$; high dose versus control, $p<0.001$; low versus control, $p<0.01$; high versus low dose, $p<0.05)$. During the $4 \mathrm{~h}$ short-term spatial working memory tests (5th treatment week) the performance of the treated rats was significantly and dose-dependently lower than in the controls $\left(F_{2,9}=16.85\right.$; high dose versus control, $p<0.001$; low versus control, $p<0.05$; high versus low dose, $p<0.05)$. After a 2 weeks rest period, the control and low dose group both showed a memory return to the level seen on the 2 nd week but the level reached by the high dose animals was markedly less. In the long-term spatial working memory test (9th treatment week), both $\mathrm{MnCl}_{2}$ treated groups showed a further significant memory deficit versus control $\left(F_{2,12}=26.14 ; p<0.001\right)$ and the high versus low difference was also significant $(p<0.001)$. On comparison of the longterm (9th and 10th week) and short-term (3rd and 5th week) memory retention it was found that the group receiving low dose Mn had a better performance in the 9th than in the 3rd week. All other differences were insignificant.

At the end of the 10th week, Mn administration was finished. In the 3rd post-treatment week, memory return in the high dose group was, compared to the 8th treatment week, greatly improved. In the repeated long-term spatial working memory test, however, no noteworthy change in any of the treated groups was seen.

\subsection{Open field activity}

In the open field activity, $\mathrm{MnCl}_{2}$ treated animals had decreased spontaneous activities.

Horizontal activity (running) of the treated animals decreased in the 5th and 10th treatment week in a dose- and time-dependent manner versus untreated (or versus 0th week) controls (Fig. 2A; $F_{4,72}=11.04$; 5 th week: both doses versus control, $p<0.01$; 10th week: both doses versus control, $p<0.05)$. The interaction of dose and treatment time was not significant $\left(F_{4,72}=2.17\right.$; n.s. $)$.

Decrease of the local activity (consisting predominantly of grooming; Fig. 2B) became significant by the 10th week $\left(F_{4,72}=3.18\right.$; both doses versus control, $\left.p<0.01\right)$. Interaction of doses and treatment times: $F_{4,72}=1.98$; n.s.

Vertical activity (the number of rearings; Fig. 2C) was reduced in a dose- and time-dependent manner versus controls by the 5 th week $\left(F_{4,72}=7.19\right.$; both doses versus control, $p<0.001$; interaction: $F_{4,72}=2.17$; n.s.). In the 10 th week, near-control levels of vertical activity was seen. 

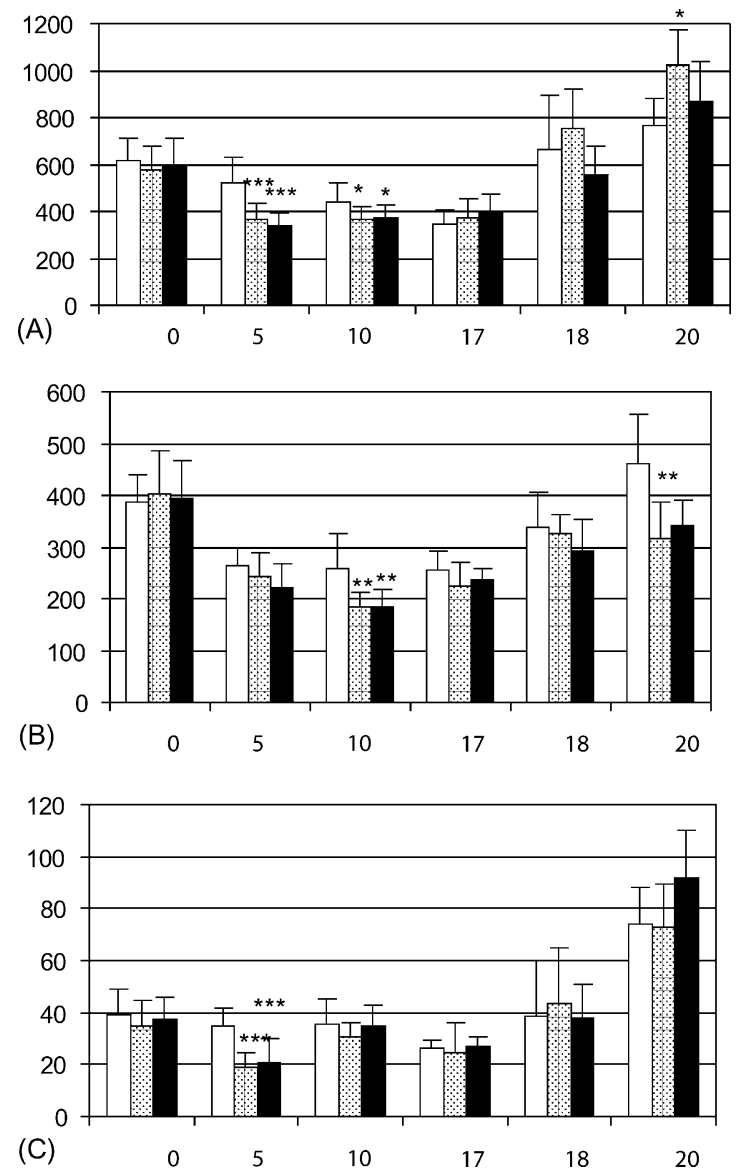

Fig. 2. Open field performance (A) horizontal activity [running]; (B) local activity [predominantly grooming]; (C) vertical activity [rearing] in different phases of the experiment in control and treated rats. Abscissa: weeks of the experiment: 0 (pre-treatment week), 5, 10 (5th and 10th treatment week), $17,18,20$ (7th, 8th and 10th post-treatment week). Ordinate: (A) length run, $\mathrm{cm}$; (B) count, local activity; (C) count, rearing. Numerical performance value (mean \pm S.D.), note different scales and units. ${ }^{*},{ }^{* *},{ }^{* * *}: p<0.05$, $0.01,0.001$ vs. control. Bar pattern as in Fig. 1 .

After 7 weeks without treatment the difference between the control and treated groups was minimal in all three forms of activity. These records were used as controls versus those taken in the 8th and 10th post-treatment week (18th and 20th week of the experiment), when the effect of two doses of D-A on the open field activity of the control and high- and lowdose $\mathrm{MnCl}_{2}$ treated rats was studied (Fig. 2A-C, columns for week 17 and later). In the 8th post-treatment week, $0.5 \mathrm{mg} / \mathrm{kg}$ D-A was given to the rats i.p., which caused no significant alteration in the rearing, grooming and horizontal activity of both treated groups, compared either to the untreated control group or to the data of the same group before D-A administration.

Allowing 2 weeks for D-A to disappear, this test was repeated on the 10th post-treatment week with a higher dose $(1.5 \mathrm{mg} / \mathrm{kg}$ ). Here, local activity (Fig. 2B) decreased in both treated groups $\left(F_{2,12}=5.42\right.$; low dose versus control, $p<0.01$; high dose, n.s.). Horizontal activity (Fig. 2A) showed an increasing trend in both groups versus control but the effect was significant only in the low dose group $\left(F_{2,12}=4.15 ; p<0.05\right)$. The high dose group also showed clearly (albeit not significantly) increased vertical activity after $1.5 \mathrm{mg} / \mathrm{kg}$ D-A (Fig. 2C).

In the horizontal activity, comparison of the data of the 7th, 8th and 10th post-treatment week revealed a significant effect of the $\mathrm{MnCl}_{2}$ dose $\left(F_{4,36}=3.43, p<0.05\right)$ and of D-A administration $\left(F_{4,36}=51.05, p<0.001\right)$. In the local (grooming) activity, comparison of the data of the same post-treatment weeks revealed a significant effect of $\mathrm{MnCl}_{2}$ dose $\left(F_{4,36}=5.69, p<0.01\right)$ and of D-A administration $\left(F_{4,36}=20.63, p<0.001\right)$.

\subsection{Acoustic startle response and pre-pulse inhibition}

In the 10th treatment week, the effect of $\mathrm{Mn}$ on the number (Fig. 3) and measured parameters (onset latency, peak time, peak amplitude; Table 3) of the "noise positive" acoustic startle responses (defined in Section 2.3.4) was below significance. Mn dose-dependently reduced the number of acoustic responses given on 10 consecutive stimuli (Fig. 3A; $\chi^{2}=16.63, p<0.01$ ). The effect of the pre-pulse inhibition-indicating sensorimotor gating-was strong in the control group, but in both treated groups it was changed to facilitation (i.e. more responses than without pre-pulse, $\chi^{2}=22.98, p<0.01$; Fig. 3B versus A). In the 7th posttreatment week, the number of ASR responses in each of the groups was not significantly different from the values in the 10th treatment week (Fig. 3C), the reaction of the treated rats was again significantly different from the controls $\left(\chi^{2}=9.75\right.$, $p<0.05)$. Now, the pre-pulses exerted their inhibiting action both in the treated and control groups making the betweengroup differences insignificant (Fig. 3D; $\chi^{2}=0.55, p>0.05$ ).

The alterations in the measurable parameters of the ASR of the control and Mn-treated animals in the 10th treatment and 7 th post-treatment week were moderate. In the 10th treatment week (Table 3A), onset latency increased significantly in both treated groups versus control $\left(F_{2,24}=4.06 ; p<0.05\right.$ for both groups versus control). Peak amplitude decreased in the treated groups but the change was not significant and was stronger in the low than in the high dose group. Prepulse inhibition in the treated groups was paradox also on these parameters: the startle responses became faster and stronger $\left(F_{2,23}=10.01\right.$; low dose versus control, $p<0.001$; high, $p<0.01$ ). After 7 weeks of treatment (Table 3B) most of the effects were still present but the paradoxical effect of the pre-pulse was no more seen. ASR latency: $F_{2,14}=8.20$; high dose versus control, $p<0.01$; high versus low dose, $p<0.05$. ASR peak time: $F_{2,14}=11.58$; high dose versus control, $p<0.001$; high versus low dose, $p<0.01$.

\subsection{Electrophysiological parameters}

In the spontaneous cortical and hippocampal activity, there were minor, non-significant changes in the power 

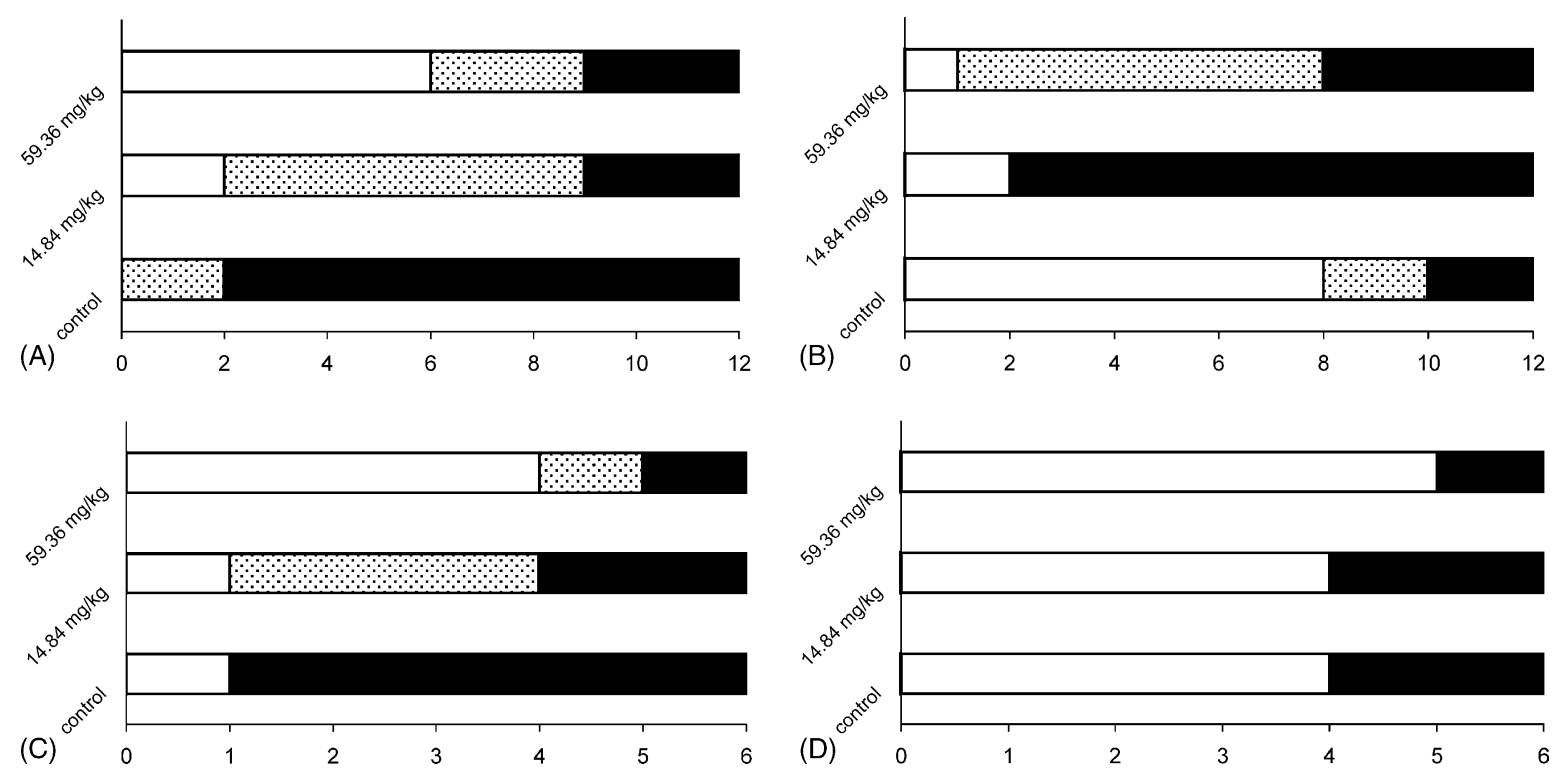

Fig. 3. Number of positive startle responses given on $110 \mathrm{~dB}$ acoustic stimulus, without (A, C) and with (B, D) pre-pulse inhibition, at the end of the treatment period (10th week, top) and in the 7th week of the post-treatment period (bottom), in control and treated (low dose, $14.84 \mathrm{mg} / \mathrm{kg}$; high dose, $59.36 \mathrm{mg} / \mathrm{kg}$ ) rats. The bars show the distribution of rats ( $n=12$ per group in the 10th treatment week, and $n=6$ per group in the 7 th post-treatment week) according to the number

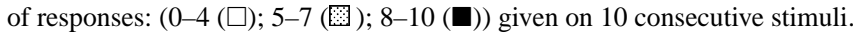

distribution over the frequency range on Mn application (Fig. 4A-D). The general trend was increase in the theta and decrease in the beta2 and gamma bands but the dosedependence was not clear. In the 12th post-treatment week (Fig. 4E-H), the changes of the spontaneous activity in the cortex disappeared but the decrease in the beta2 and gamma band of the hippocampal activity became more expressed.

In the sensory EPs, the general effect after 10 weeks Mn administration (Fig. 5A-C) was a lengthening of the latency (significant in the somatosensory and visual EP, $p<0.05$ ). The alteration of the duration was mostly negligible. After 12

Table 3

Measured parameters of the acoustic startle response in control and treated animals after 10 weeks Mn administration (A) and after subsequent 7 weeks elimination (B)

\begin{tabular}{|c|c|c|c|}
\hline & \multirow[t]{2}{*}{ Control } & \multicolumn{2}{|l|}{$\mathrm{MnCl}_{2}$} \\
\hline & & $14.84 \mathrm{mg} / \mathrm{kg}$ & $59.36 \mathrm{mg} / \mathrm{kg}$ \\
\hline \multicolumn{4}{|c|}{ (A) Startle response in the 10 th week of the treatment period } \\
\hline \multicolumn{4}{|c|}{ Acoustic startle response } \\
\hline Onset latency (ms) & $19.384 \pm 1.8209(n=9)$ & $22.095 \pm 1.5013^{*}(n=9)$ & $21.694 \pm 2.9442^{*}(n=9)$ \\
\hline Peak time (ms) & $26.709 \pm 1.5104(n=9)$ & $27.491 \pm 2.0387(n=9)$ & $27.127 \pm 1.8735(n=9)$ \\
\hline Peak amplitude (g) & $285.794 \pm 150.9(n=9)$ & $153.076 \pm 71.1477(n=9)$ & $252.200 \pm 154.15(n=9)$ \\
\hline \multicolumn{4}{|c|}{ ASR with pre-pulse inhibition } \\
\hline Onset latency (ms) & $23.221 \pm 1.8558(n=8)$ & $19.520 \pm 1.7919^{* * * *}(n=9)$ & $19.837 \pm 1.9564^{* * *}(n=9)$ \\
\hline Peak time (ms) & $26.711 \pm 1.6376(n=8)$ & $25.812 \pm 1.0045(n=9)$ & $25.911 \pm 1.4715(n=9)$ \\
\hline Peak amplitude (g) & $128.130 \pm 125.96(n=8)$ & $203.648 \pm 72.635(n=9)$ & $185.696 \pm 100.45(n=9)$ \\
\hline \multicolumn{4}{|c|}{ (B) Startle response in the 7th week of the post-treatment period } \\
\hline \multicolumn{4}{|c|}{ Acoustic startle response } \\
\hline Onset latency (ms) & $19.182 \pm 1.3883(n=6)$ & $20.800 \pm 1.3509(n=6)$ & $23.826 \pm 2.8222^{* *, \#}(n=6)$ \\
\hline Peak time (ms) & $25.527 \pm 1.1923(n=6)$ & $27.060 \pm 0.9581(n=6)$ & $30.56 \pm 2.724^{* * *, \# \#}(n=6)$ \\
\hline Peak amplitude (g) & $197.030 \pm 64.9463(n=6)$ & $203.494 \pm 57.2813(n=6)$ & $188.680 \pm 100.367(n=6)$ \\
\hline \multicolumn{4}{|c|}{ ASR with pre-pulse inhibition } \\
\hline Onset latency (ms) & $21.951 \pm 3.708(n=5)$ & $22.536 \pm 1.3707(n=5)$ & $25.250 \pm 4.3373(n=5)$ \\
\hline Peak time (ms) & $28.207 \pm 3.6450(n=5)$ & $28.260 \pm 0.7829(n=5)$ & $29.800 \pm 2.7055(n=5)$ \\
\hline Peak amplitude (g) & $214.761 \pm 120.709(n=5)$ & $155.970 \pm 113.5942(n=5)$ & $90.567 \pm 55.0914(n=5)$ \\
\hline
\end{tabular}

Onset latency, peak time and peak amplitude were determined from the time course of the force, exerted by the startled rat on the cage bottom. Mean \pm S.D.; $n$, animals investigated in each group. *, **, ***: $p<0.05,0.01,0.001$ vs. control; \#, \#\#: $p<0.05,0.01$ high vs. low dose. 

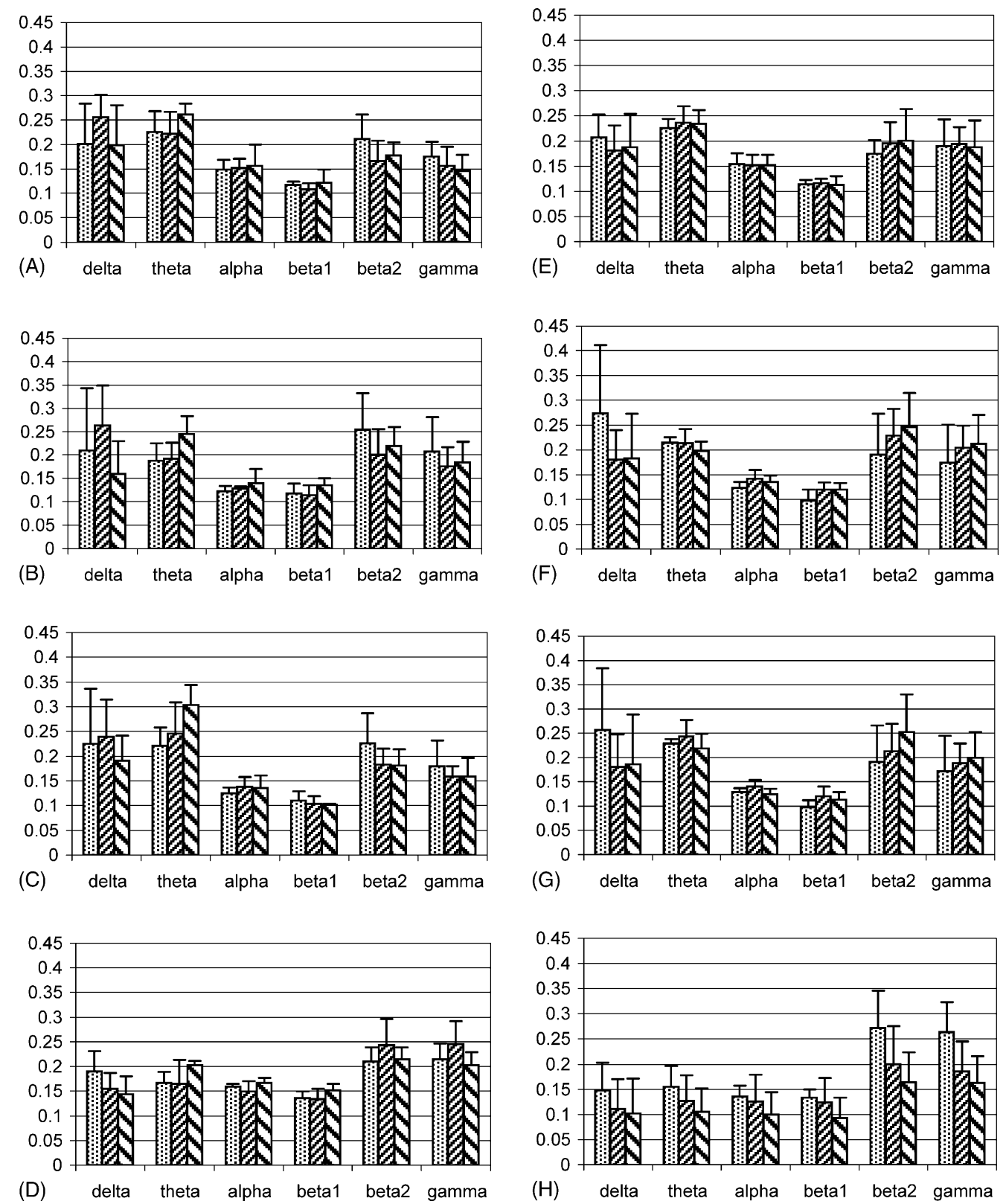

Fig. 4. Power spectrum of the rats' spontaneous cortical and hippocampal electrical activity, in the 10th treatment week (left column: (A) somatosensory; (B) visual; (C) auditory cortex; (D) hippocampal CA1) and in the 12th post-treatment week (right column: (E) somatosensory; (F) visual; (G) acoustic cortex; (H) hippocampal CA1). Abscissa: ECoG frequency bands. Ordinate: relative power, mean \pm S.D. Bar pattern: control (雨); low dose $(\mathbb{Z})$; high dose $(\mathbf{S})$.

weeks without Mn administration (Fig. 5D-F), some of the effects disappeared (on the somatosensory EP) while others remained (on the visual EP).

\subsection{Immunhistochemistry}

In the density of GFAP immunoreactive structures in the hippocampal CA1 region of the investigated rats, no differences were seen between the control animals and those treated with low and high dose of $\mathrm{MnCl}_{2}$. However, in the hilar part of the dentate gyrus, there was an increase of GFAP-IR density at both concentrations of manganese treatment (Fig. 6).

\section{Discussion}

Subchronic administration of $\mathrm{MnCl}_{2}$ to the rats in this study resulted in marked internal exposure (shown by the $\mathrm{Mn}$ levels in the cortex and hippocampus; Table 2). Mn levels in the control rats' brains, originating from the background $\mathrm{Mn}$ present in standard food and drinking water, were similar to that described earlier by Rehnberg et al. (1982).

From the gastrointestinal tract, absorption of ionic $\mathrm{Mn}$ is low $(<10 \%)$ and self-limited in the rats (Davis et al., 1992). Once absorbed, $\mathrm{Mn}$ is bound to plasma proteins and is readily taken up into the CNS, as a free ion or in transferrin- 


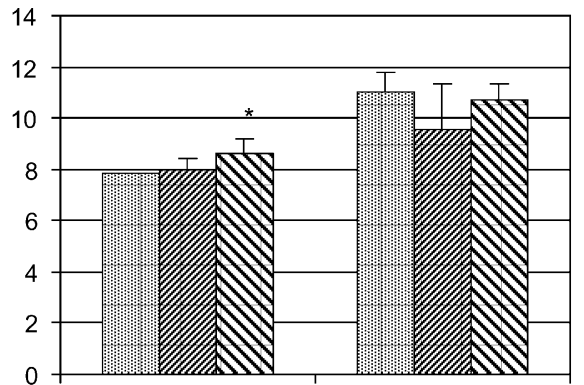

(A)

lat.

dur.

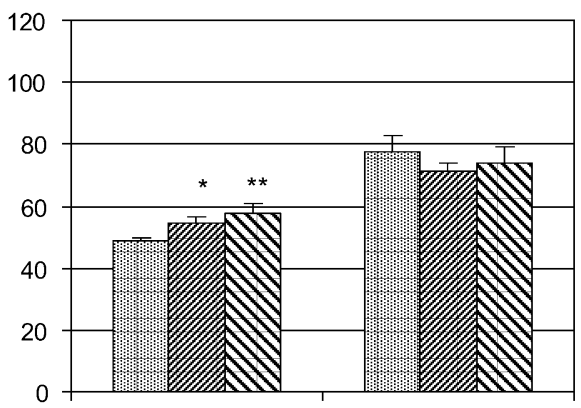

(B)

lat.

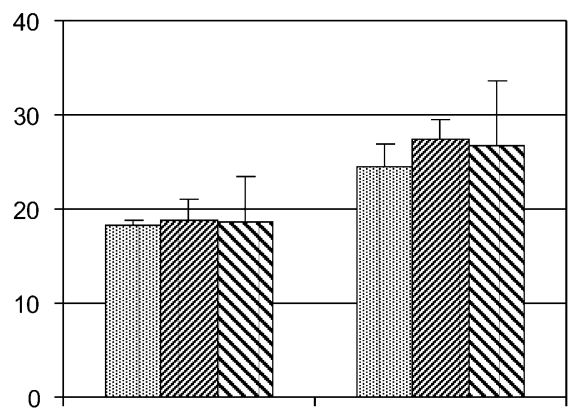

(C)

dur.

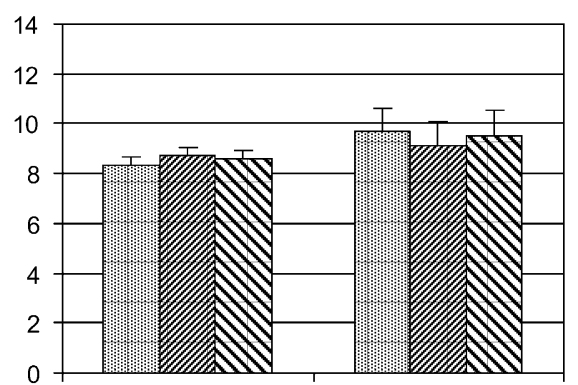

(D)

lat.

dur.

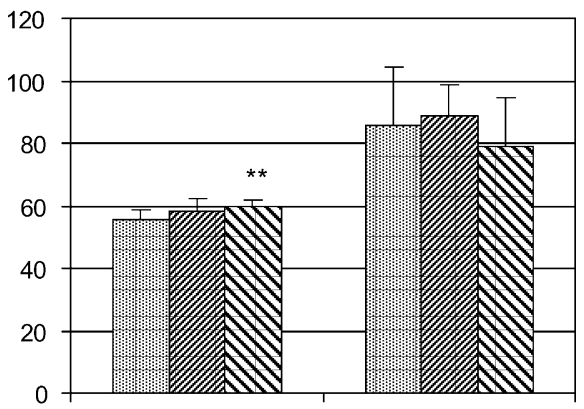

(E)

lat.

dur.

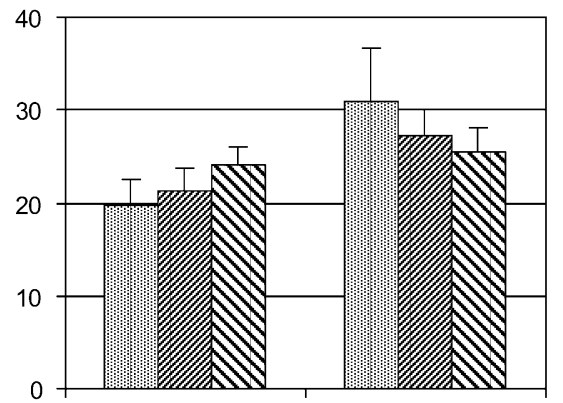

(F)

dur.

Fig. 5. Latency and duration of the sensory evoked potentials in the 10th treatment week (left column: (A) somatosensory; (B) visual; (C) auditory EP) and in the 12th post-treatment week (right column: (D) somatosensory; (E) visual; (F) auditory EP). Ordinate: latency (lat.) and duration (dur.) in ms, mean \pm S.D. * , ${ }^{* *}: p<0.05,0.01$ treated vs. control. Bar pattern as in Fig. 4.

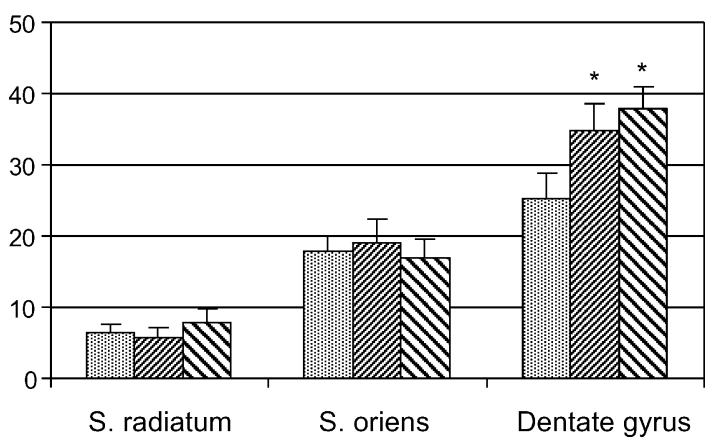

Fig. 6. Presence of GFAP-immunoreactive elements in different parts of the hippocampus (stratum radiatum and stratum oriens of CA1, and hilus of the dentate gyrus) in control and treated rats in the 10th week of treatment. Ordinate: GFAP positivity in percent of the total area (mean \pm S.D., on the basis of numerous sections from two animals per group). ${ }^{*}: p<0.05$ treated vs. control. Bar pattern as in Fig. 4. bound form (Aschner and Gannon, 1994). There is a slow shift of Mn from the parenchymal organs to the CNS where Mn will be deposited. Elimination of Mn from the CNS, first of all from the cerebrum, is much slower than from the whole body (Cotzias et al., 1968). Following a shorter exposure by doses similar to what was given in our work, Mn levels in the typically affected parts of the brain (striatum, hypothalamus, nucleus accumbens) were not paralleled by the levels of transmitters and their metabolites (Kontur and Fechter, 1988); indicating that the brain has some capacity of compensating the adverse effects of Mn.

Among the cell types constituting the brain tissue, $\mathrm{Mn}$ is accumulated in astrocytes, crucial in neutralizing glutamate released in the glutamatergic (e.g. thalamocortical) synapses. This process was inhibited in astrocytes exposed to elevated $\mathrm{Mn}^{2+}$ (Normandin and Hazell, 2002), resulting first in overstimulation then in desensitization or down-regulation of glu- 
tamate receptors, possibly leading to the latency lengthening of the cortical EP seen by us. Alterations of evoked responses in Mn-exposed humans have also been described together with changes in the EEG. The latter has a well-known activating cholinergic modulation (Metherate et al., 1992) and if the elevated $\mathrm{Mn}$ level in the brain reduces the activity of choline acetyltransferase (Lai et al., 1981), the ascending activating input can be diminished. The slight changes of cortical and hippocampal activity observed in our study were in line with the above.

The hippocampal formation (with retrosplenial cortex and dorsal striatum), is a preferential site of Mn accumulation, and is an important neural axis responsible for spatial memory and reward-based learning. In our experiments, the performance in acquisition, short-term retention tasks and long-term spatial working memory - a stable and reliable phenomenon in rats-was significantly decreased in the $\mathrm{MnCl}_{2}$-administered animals in the 10th treatment week, indicating functional damage. A possible morphological counterpart, gliotic degeneration, was in fact seen in the dentate gyrus, in both treated groups in the 10th week. The dentate gyrus and CA1 areas of the hippocampus, are integral neural substrates in the acquisition of new information, hence important loci for spatial learning and working memory processes (Eyre et al., 2003). In our work, elevated hippocampal Mn level and altered frequency spectrum of the hippocampal spontaneous electrical activity was seen at the end of the 10th week of Mn exposure.

The rats' extrapyramidal motor control (Bonilla, 1984), and the sensorimotor integration, is dependent on the mesolimbic and nigrostrial dopaminergic system (Fink and Smith, 1980), both known to show dysfunction on Mn application. In our experiments, decrease of the spontaneous horizontal and vertical activity in the open field was seen in the 5th, and of the local activity in the 10th, week of treatment. The number of "noise-positive" ASR responses decreased, and their onset latency increased, in the Mn-treated animals in the 10th week. Sensorimotor gating was, however, reduced in both $\mathrm{Mn}$-treated groups at the end of treatment, so that the pre-pulse inhibition was inverted to facilitation (shown by the number of responses and by the peak time, see Fig. 3 and Table 3). In the cholinergic neurons of the pedunculopontine tegmental nucleus, an important part of the PPI circuit (Swerdlow and Geyer, 1993) neurotoxic lesion by Mn has been described (Tomas-Camardiel et al., 2002), resulting in significantly reduced PPI without affecting the startle magnitude in the absence of a pre-pulse (Jones and Shannon, 2000).

During the post-treatment period, elimination of the Mn from the cortex and hippocampus was seen. The cortical and hippocampal Mn levels were falling more in the high dose than in the low dose group during the post-treatment period, and some effects of Mn showed inverted dose dependence in this period, which may be due to the dose-dependently increasing elimination of Mn (Mena et al., 1967). The majority of behavioral effects, however, remained. In the repeated long-term spatial memory test, significantly decreased performance was still seen in the both treated groups. In the OF activity of the control and treated rats, no more difference was detected, but by injecting $1.5 \mathrm{mg} / \mathrm{kg}$ D-A, the residual effects of $\mathrm{Mn}$-substantial increase of the horizontal and vertical, and decrease of the local activity-were revealed (Fig. 2). In the horizontal and local activity, the effect was stronger in the low-dose group, possibly due to the dose-dependent elimination mentioned above.

In 7th post-treatment week, the magnitude of the ASR was still diminished but the reduction of pre-pulse inhibition was no more seen. The alterations of the spontaneous cortical activity had a similar time course indicating that the effect of $\mathrm{Mn}$ on the cholinergic system was probably responsible for both.

\section{Conclusion}

The main points of conclusion drawn from the above results are as given below.

Oral $\mathrm{MnCl}_{2}$ treatment, 14.84 and $59.36 \mathrm{mg} / \mathrm{kg}$ b.w., for 10 weeks brought about, primarily in the high-dose group, an increase in first the blood, then cortex and hippocampus Mn levels.

During the treatment period, altered PPI and cortical spontaneous activity in the treated rats suggested the involvement of brainstem cholinergic systems (pre-pulse inhibition pathway and ascending cortical activation) due to Mn-induced damage. The alterations in maze learning, open field activity and ASR magnitude suggested the decrease of certain other neurotransmitter levels (e.g. DA or Glu) in the centers responsible for these behavioral functions, pointing to the involvement of the glutamatergic auditory pathway and the nigrostriatal dopaminergic system, and possibly to neuropathological changes in some components of the neural axis for behavior (e.g. hippocampal formation). The changes in the cortical EPs also indicated the involvement of the glutamatergic afferent pathways. In the treated rats, gliosis was found in the hilar part of the dentate gyrus compared to the controls.

In the post-treatment period, Mn levels in all tissue samples from the previously treated animals returned to the control. The alterations of the long-term spatial memory, the open field activity and the ASR reaction, however, remained. This indicated a long-lasting effect of $\mathrm{Mn}$ on these functions, although the dose-effect relationship elimination was in some cases anomalous.

By applying a complex set of methods, it was possible to obtain new data for a better-based relationship between the known effects of $\mathrm{Mn}$ at neuronal level and the behavioral and electrophysiological outcomes of $\mathrm{MnCl}_{2}$ exposure observed in our study and described in the literature. Taking into account that some of the effects proved to outlast the period of exposure, and the importance of the probably involved systems in the higher-order nervous functions of humans, the 
neurotoxic risk of environmental and/or occupational $\mathrm{MnCl}_{2}$ exposure seems to deserve ongoing attention.

\section{References}

Aschner, M., Gannon, M., 1994. Manganese (Mn) transport across the rat blood-brain barrier: saturable and transferrin-dependent transport mechanisms. Brain Res. Bull. 33, 345-349.

Aschner, M., Vrana, K.E., Zheng, W., 1999. Manganese uptake and distribution in the central nervous system (CNS). Neurotoxicology 20, 173-180.

Aschner, M., 1996. The functional significance of brain metallothioneins. FASEB J. 10, 1129-1136.

ATSDR, 2000. Toxicological Profile for Manganese. US Department of Health and Human Services, Atlanta, GA, USA, pp. 336-338.

Baeck, S.Y., Lee, M.-J., Jung, H.-S., Kim, H.-J., Lee, C.-R., Yoo, C., Lee, J.H., Lee, H., Yoon, C.S., Kim, Y.H., Park, J., Kim, J.-W., Jeon, B.S., Kim, Y., 2003. Effect of manganese exposure on MPTP neurotoxicities. Neurotoxicology 24, 657-665.

Barceloux, D.G., 1999. Manganese. Clin. Toxicol. 37, 293-307.

Barlow, P.J., 1983. A pilot study on the metal levels in the hair of hyperactive children. Med. Hypotheses 11, 309-318.

Beatty, W.W., Shavalia, D.A., 1982. Spatial memory in rats: time course of working memory and effect of anesthetics. Behav. Neural Biol. 28, 454-462.

Bonilla, E., 1984. Chronic manganese intake induces changes in the motor activity of rats. Exp. Neurol. 84, 696-700.

Bowman, W.C., Rand, M.J., 1980. Textbook of Pharmacology. Blackwell Scientific Publications, Oxford, pp. 7-15.

Calabresi, P., De Murtas, M., Bernardi, G., 1997. The neostriatum beyond the motor function: experimental and clinical evidence. Neuroscience $78,39-60$.

Chan, A.W.K., Minski, M.J., Lim, L., Lai, J.C., 1992. Changes in brain regional manganese and magnesium levels during postnatal development: modulations by chronic manganese administration. Metab. Brain Dis. 7, 21-33.

Clarkson, P.B., Jakubovic, A., Fibiger, H.C., 1988. Anatomical analysis of the involvement of mesolimbocortical dopamine in the locomotor stimulant actions of D-amphetamine and apomorphine. Psychopharmacology 96, 511-520.

Cotzias, G.C., Horiuchi, K., Fuenzalida, S., Mena, I., 1968. Chronic manganese poisoning: clearance of tissue manganese concentrations with persistence of the neurological picture. Neurology 18, 376-382.

Cotzias, G.C., Papavasiliou, P.S., Ginos, J., Steck, A., Duby, S., 1971. Metabolic modification of Parkinson's disease and of chronic manganese poisoning. Annu. Rev. Med. 22, 305-326.

Davis, C.D., Wolf, T.L., Greger, J.L., 1992. Varying levels of manganese and iron affect absorption and gut endogenous losses of manganese by rats. J. Nutr. 122, 1300-1308.

Deschamps, F.J., Guillamot, M., Raux, S., 2001. Neurological effects in workers exposed to manganese. J. Occup. Environ. Med. 43, 127132.

Dorman, D.C., Stuve, M.F., Vitarella, D., Byerly, F.L., Goetz, J., Miller, R., 2000. Neurotoxicity of manganese chloride in neonatal and adult $\mathrm{CD}$ rats following subchronic (21-day) high-dose oral exposure. J. Appl. Toxicol. 20, 179-187.

Erikson, K., Aschner, M., 2002. Manganese causes differential regulation of glutamate transporter (GLAST) taurine transporter and metallothionein in cultured rat astrocytes. Neurotoxicology 23, 595-602.

Eyre, M.D., Richter-Levin, G., Avital, A., Stewart, M., 2003. Morphological changes in hippocampal dentate gyrus synapses following spatial learning in rats are transient. Eur. J. Neurosci. 17, 1973-1980.

Feifel, D., Reza, T., Robeck, S., 1999. Antipsychotic potential of CCKbased treatments: an assessment using the prepulse inhibition model of psychosis. Neuropsychopharmacology 20, 141-149.
Feldman, R.G., 1992. Manganese. In: de Wolff, F.A. (Ed.), Handbook of Clinical Neurology: Intoxications of the Nervous System, Part I, vol. 20. Elsevier, Amsterdam, pp. 303-322.

Fink, J.S., Smith, G.P., 1980. Relationships between selective denervation of dopamine terminal fields in the anterior forebrain and behavioral responses to amphetamine and apomorphine. Brain Res. 201, 107127.

Graham, F., 1975. The more-or-less startling effects of weak prestimuli. Psychophysiology 12, 238-248.

Gwiazda, R.H., Lee, D., Sheridan, J., Smith, D.R., 2002. Low cumulative manganese exposure affects strial GABA but not dopamine. Neurotoxicology 23, 69-76.

Hazell, A.S., 2002. Astrocytes and manganese neurotoxicity. Neurochem. Int. 41, 271-277.

Hernandez, E.H., Discalzi, G., Dassi, P., Jarre, L., Pira, E., 2003. Manganese intoxication: the cause of an inexplicable epileptic syndrome in a 3 year old child. Neurotoxicology 24, 633-639.

Ikegaya, Y., Abe, K., Saito, H., Nishiyama, N., 1995. Medial amygdala enhances synaptic transmission and synaptic plasticity in the dentate gyrus of rats in vivo. J. Neurophysiol. 74, 2201-2203.

Ingersoll, R.T., Montgomery, E.B., Aposhian Jr., H.V., 1995. Central nervous system toxicity of manganese. I. Inhibition of spontaneous motor activity in rats after intrathecal administration of manganese chloride. Fundam. Appl. Toxicol. 27, 106-113.

Jones, C.K., Shannon, H.E., 2000. Muscarinic cholinergic modulation of prepulse inhibition of the acoustic startle reflex. JPET 294, 1017-1023.

Kandel, E.R., Schwartz, J.H., 1985. Principles of Neural Science. Elsevier, New York, pp. 643-644.

Kondakis, X.G., Makris, N., Leotsinidis, M., Papapetropoulos, T., 1989. Possible health effects of high manganese concentration in drinking water. Arch. Environ. Health 44, 175-178.

Kontur, P.J., Fechter, L.D., 1988. Brain regional manganese levels and monoamine metabolism in manganese-treated neonatal rats. Neurotox. Teratol. 10, 295-303.

Lai, J.C., Leung, T.K., Lim, L., 1981. Brain regional distribution of glutamic acid decarboxylase, choline acetyltransferase, and acetylcholinesterase in the rat: effects of chronic manganese chloride administration after two years. J. Neurochem. 36, 1443-1448.

Lucchini, R., Apostoli, P., Perrone, C., Placidi, D., Albini, E., Migliorati, P., Mergler, D., Sassine, M.P., Palmi, S., Alessio, L., 1999. Long-term exposure to "low levels" of manganese oxides and neurofunctional changes in ferroalloy workers. Neurotoxicology 20, 287-297.

Marlowe, M., Bliss, L., 1993. Hair element concentrations and young children's behavior at school and home. J. Orthomol. Med. 9, 1-12.

Mena, I., Marin, O., Fuenzalida, S., Cotzias, G.C., 1967. Chronic manganese poisoning: clinical picture and manganese turnover. Neurology $17,128-136$

Mergler, D., Baldwin, M., Belanger, S., Larribe, F., Beuter, A., Bowler, R., Panisset, M., Edwards, R., de Geoffroy, A., Sassine, M.-P., Hudnell, K., 1999. Manganese neurotoxicity, a continuum of dysfunction: results from a community based study. Neurotoxicology 20, 327342.

Metherate, R., Cox, C.L., Ashe, J.H., 1992. Cellular bases of neocortical activation: modulation of neural oscillations by the nucleus basalis and endogenous acetylcholine. J. Neurosci. 12, 4701-4711.

Neff, N.H., Barrett, R.E., Costa, E., 1969. Selective depletion of caudate nucleus dopamine and serotonin during chronic manganese dioxide administration to squirrel monkeys. Experientia 25, 1140-1141.

Normandin, L., Hazell, A.S., 2002. Manganese neurotoxicity: an update of pathophysiologic mechanisms. Metab. Brain Dis. 17, 375387.

Ogura, H., Yasuda, M., Nakamura, S., Yamashita, H., Mikoshiba, K., Ohmori, H., 2002. Neurotoxic damage of granule cells in the dentate gyrus and the cerebellum and cognitive deficit following neonatal administration of phenytoin in mice. J. Neuropathol. Exp. Neurol. 61, 956-967. 
Öner, G., Sentürk, Ü.K., 1992. The mechanism of manganese induced learning disability. J. Islamic Acad. Sci. 5, 49-52.

Pappas, B.A., Zhang, D., Davidson, C.M., Crowder, P., Park, G.A., Fortin, T., 1997. Perinatal manganese exposure: behavioral, neurochemical and histopathological effects in rat. Neurotox. Teratol. 19, 1725.

Parenti, M., Rusconi, L., Cappabianca, V., Parati, E.A., Gropetti, A., 1987. Role of dopamine in manganese neurotoxicity. Brain Res. 473, 236-240.

Paxinos, G., Watson, C., 1982. The Rat Brain in Stereotaxic Coordinates. Academic Press, New York.

Physical and Theoretical Chemistry Laboratory, 2001. Safety Data for Manganese(II) Chloride Tetrahydrate. http://physchem.ox.ac.uk/ MSDS, Oxford, UK.

Quaghebeur, G., Taylor, W.J., Kingsley, D.P.E., Fell, J.M.E., Reynolds, A.P., Milla, P.J., 1996. MRI in children receiving total parenteral nutrition. Neuroradiology 38, 680-683.

Rehnberg, J.L., Hein, J.F., Carter, S.D., Linko, R.S., Laskey, J.W., 1982. Chronic ingestion of $\mathrm{Mn}_{3} \mathrm{O}_{4}$ by rats: tissue accumulation and distribution of manganese in two generations. J. Toxicol. Environ. Health 9, 175-188.

Roels, H., Lauwerys, R., Buchet, J.P., Genet, P., Sarhan, M.J., Hanotiau, I., de Fays, M., Bernard, A., Stanescu, D., 1987. Epidemiological survey among workers exposed to manganese: effects on lung, central nervous system, and some biological indices. Am. J. Ind. Med. 11, 307-327.

Sinczuk-Walczak, H., Jakubowski, M., Matczak, W., 2001. Neurological and neurophysiological examinations of workers occupationally exposed to manganese. Int. J. Occup. Med. Environ. Health 14, 329-337.

Subhash, M.N., Padmashree, T.S., 1991. Effect of manganese on biogenic amine metabolism in regions of the rat brain. Food Chem. Toxicol. $29,579-582$.
Swerdlow, N.R., Geyer, M.A., 1993. Prepulse inhibition of acoustic startle in rats after lesions of the pedunculopontine tegmental nucleus. Behav. Neurosci. 107, 104-117.

Takeda, A., Sawashita, J., Okada, S., 1998. Manganese concentration in rat brain: manganese transport from the peripheral tissues. Neurosci. Lett. 242, 45-48.

Takeda, A., Sotogaku, N., Oku, N., 2002. Manganese influences the levels of neurotransmitters in synapses in rat brain. Neuroscience 114, 669-674.

Takser, L., Mergler, D., Hellier, G., Sahuquillo, J., Huel, G., 2003. Manganese, monoamine metabolite levels at birth, and childhood psychomotor development. Neurotoxicology 24, 667-674.

Tomas-Camardiel, M., Herrera, A.J., Venero, J.L., Cruz Sanchez-Hidalgo, M., Cano, J., Machado, A., 2002. Differential regulation of glutamic acid decarboxylase mRNA and tyrosine hydroxylase mRNA expression in the aged manganese-treated rats. Mol. Brain Res. 103, 116-129.

Tran, T.T., Chowanadisai, W., Lonnerdal, B., Le, L., Parker, M., ChiczDemet, A., Crinella, F.M., 2002. Effects of neonatal dietary manganese exposure on brain dopamine levels and neurocognitive functions. Neurotoxicology 23, 645-651.

Trepper, M.J., Paladini, C.A., Celada, P., 1998. Gabaergic control of the firing pattern of substantia nigra dopaminergic neurons. Adv. Pharmacol. 42, 694-699.

WHO, 1981. Manganese. Environmental Health Criteria 17. World Health Organisation, Geneva.

Yamada, M., Ohno, S., Okayasu, I., Okeda, R., Hatakeyama, S., Watanabene, H., Ushio, K., Tsukagoshi, H., 1986. Chronic manganese poisoning: a neuropathological study with determination of manganese distribution. Acta Neuropathol. 70, 273-278.

Zilles, K., 1984. The Cortex of the Rat. A Stereotaxic Atlas. Springer, Berlin. 